\title{
Is the district nursing service in a position to deliver intermediate care? A national survey of district nursing provision
}

Margaret Edwards and Liz Dyson Florence Nightingale School of Nursing and Midwifery, King's College London, UK

\begin{abstract}
The government intends to invest heavily in intermediate care services by the year 2004. The term 'intermediate care' defies precise definition, but is said to include a number of community-based services, including those provided by district nurses. Enhanced district nursing may be one solution to providing care for many elderly patients who are thought to be inappropriately admitted to acute hospitals. The feasibility of this option has yet to be tested, but district nursing enjoys public confidence and is well placed within the primary care framework to ensure continuity of care. This paper describes a national postal survey of district nursing provision within all community trusts in England conducted in 1998 to explore a picture of the structural and organizational factors which impinge on the delivery of intermediate care by district nurses. The Handbook of Community Nursing was used to identify those with designated responsibility for district nursing within trusts. A response rate of $83 \%$ $(n=148)$ was attained. The majority of responding trusts reported a lack of resources to deliver more intensive levels of care. When trusts were ranked according to their performance on six key variables thought to be related to the delivery of intermediate care only two achieved the maximum score. Over half of the trusts scored 3 or less. The findings from this survey indicate a curious neglect of the district nursing service and suggest that considerable investment is needed if district nurses are to deliver an intermediate level of care.
\end{abstract}

Key words: district nursing; intermediate care; national survey

\section{Introduction}

A national survey of district nursing was conducted in 1998 to explore the structural and organizational factors within community trusts in England which would be likely to promote or inhibit the delivery of acute and intermediate nursing care in the home. The survey complemented the in-depth research into the district nursing service carried out by the Audit Commission in 1997 (Audit Commission, 1999). In addition, data were sought which had been explicitly excluded by the commissioners in their work, but were deemed relevant to the remit

Address for correspondence: Margaret Edwards, Florence Nightingale School of Nursing and Midwifery, King's College London, James Clerk Maxwell Building, 57 Waterloo Road, London SE1 8WA, UK. Email: margaret.edwards@kcl.ac.uk of this particular study, e.g., access to aids and appliances.

Since the early 1990s health care policy has explicitly favoured a shift in emphasis from hospital provision for subacute and postacute illness to the provision of such care in domicillary settings (NHS and Community Care Act, 1990; Audit Commission, 1992; DoH, 2000a). Anecdotal reports from the district nursing service suggest that in some areas district nurses are indeed having to look after more acutely sick patients at home (Audit Commission, 1999). Paradoxically, during the 1990s when numbers of the 'old' elderly were increasing, the number of district nurse education commissions fell and there was no increase in the overall numbers of personnel, qualified and unqualified, working in district nursing teams (Audit Commission, 1999). Policy makers may 
have believed that much of the work of district nurses had passed to social service departments following the NHS and Community Care Act (1990). The Audit Commission (1999) however, point to surveys conducted in individual trusts. These reported greater reliance on qualified district nurses by the increasing numbers of acute and postsurgical patients. The exponential rise in the numbers of practice nurses during the 1990s (Edwards, 1998) may also have led policy makers to believe that community nursing was well staffed even though practice nurses have never delivered the labour-intensive, seven day a week, home nursing care provided by district nurses.

Current political thinking seemingly continues to favour a 'care closer to home' scenario particularly for older people, who account for two thirds of acute hospital patients and for the growth in emergency admissions (DoH, 2000a,b). The development of intermediate care services figures prominently in the National Service Framework for Older People and there is an emphasis on rehabilitation (DoH, 2001). In considering the "care closer to home scenario' a number of models of intermediate care has been suggested, including enhanced community nursing services, beds in nursing homes, community hospitals and other intermediate care facilities. However, the feasibility of each of these models has still to be firmly established. Indeed the term 'intermediate care' itself is vaguely defined (Steiner, 1997) and is said to be best understood by what it is not, i.e., the lack of need for acute medicine/surgical intervention (Griffiths 1998). According to the Department of Health (DoH 2000a) intermediate care typically provides community-based alternatives to traditional acute hospital care.

Notwithstanding this lack of clear definition and evidence of effectiveness, an extra $£ 900$ million is to be invested in intermediate care by the year 2004 (DoH, 2000b), in particular for intermediate care beds and extra rapid response teams. Evidence from hospital at home schemes, many of which are district nurse led, suggests that such care can be delivered safely at home and on the whole are preferred by patients (Knoweldon et al., 1991; Donald et al., 1995; Wilson et al., 1999, DoH, 2000a).

Arguably, some of the resources earmarked for intermediate care could successfully be directed towards enhancing district nursing services, since evidence suggests that levels of district nursing directly and positively affect acute hospital bed usage (Carr Hill et al., 1994). One of the difficulties facing hospital at home teams and indeed other forms of intermediate care is how to integrate with primary care services (Mowat and Morgan, 1982). District nursing currently enjoys advantages over hospital at home teams and other forms of intermediate care as the service is already known to be well received by its recipients (Audit Commission, 1999). It is firmly embedded within primary health care services providing, with general practice, a level of continuity that may be more difficult for the other services to achieve. Under the Medicinal Products: Prescription by Nurses etc Act (1994) district nurses are also authorized to prescribe from a limited formulary increasing the flexibility and speed with which they can respond to patient need.

District nursing is, however, a service under pressure with an ageing workforce and inadequate manpower planning (Audit Commission, 1999). The Department of Health has now acknowledged that community nursing services have not kept pace with demographic pressures $(\mathrm{DoH}, 2000 \mathrm{a})$. The Audit Commission (1999) noted that the district nursing service, though much valued by its recipients, lacks clear service objectives. This lack of clarity, in the Commission's opinion, has led the service to be reactive rather than responsive, rarely turning away patients referred, a number of whom are unlikely to derive direct benefit from district nursing. As a consequence, according to the Commission, other patients who might benefit from the service are excluded.

In defining its service objectives, the district nursing service may need to relinquish some of its traditional areas of work as the needs of its main client group, older people, are many and various (Ryrie and Edwards, 1998). The increase in the numbers of older people make it impossible for the district nursing service to meet all their needs. Indeed there is evidence to suggest that district nursing has never been able to offer a comprehensive service to all those in need of it (Skeet, 1978). District nurses already see half the population over 85 years of age (Audit Commission, 1999). Since the NHS and Community Care Act (1990) much long-term care has been delivered by social care assistants under the guise of personal rather than health care, and some believe that there could be greater integration between district nurses and practice nurses (Young, 1999). Nonetheless, defin- 
ing service objectives around the delivery of acute and intermediate care would need to entail a consideration of the context in which district nursing operates as a number of factors impinge. District nurses themselves have been reported as questioning the expectation that they should care for more acutely sick patients discharged earlier from hospital (Audit Commission, 1999). This expressed reluctance may relate to the fact that the service is stretched and under-resourced. If the district nursing service is to formulate service objectives around the delivery of more acute or 'intermediate' levels of nursing care, a clear picture of the level of investment required is needed.

This survey therefore aimed to examine district nursing provision with particular reference to factors that could be assumed to affect the ability of the service to deliver acute or intermediate levels of care. Changes to the structure of primary health care, with the advent of primary care groups and primary care trusts (NHS Act, 1999), suggested that there would be substantial period of upheaval in the organization and delivery of community nursing services. It was envisaged that initial fragmentation of services would make it difficult to gain the necessary overview of district nursing for some time to come. This survey was therefore thought to be timely in examining the existing provision, with a view to informing both the formation of service objectives of the district nursing service and the contribution of district nursing in the longterm planning for hospitals and primary care services (DoH, 2000a).

\section{Method}

A postal survey of all the NHS trusts in England delivering community nursing services was carried out in the autumn of 1998. The Handbook of Community Nursing (1998) was used to identify 175 trusts. Questionnaires were mailed to those persons who were identified in the Handbook of Community Nursing as having responsibility for district nursing within each of the trusts. Where entries provided two or more names for distinct geographical areas within a trust questionnaires were sent to both or all. A total of 179 questionnaires were mailed.

\section{Objectives of the study}

The objectives of the study were to describe district nursing and related provision in relation to the feasibility of delivering acute and intermediate nursing care at home and to explore relationships between organizational and structural factors and levels of district nursing provision and activity.

\section{The instrument}

As district nursing is a relatively underresearched area (Audit Commission, 1999), there was little empirical evidence on which to base items relating to the delivery of intermediate care in the questionnaire. Initially items were devized by one of the authors, a district nurse with a clinical background in hospital-at-home. These items were discussed with other district nurses, including managers and practitioners currently involved with the delivery of intermediate nursing care at home via hospital at home schemes. The variables examined are presented in Figure 1, together with the rationale for inclusion. No information existed as to whether organizational factors, such as the status of the trust (whether a stand-alone community trust or one combined with an acute care or other trust) might affect the type of provision available. Items were also included around the organization of medical care, e.g., the number of GP fundholders, single-handed practices and the nature of medical night cover.

Although GP fundholding was about to end under the proposals for the new NHS it was included as an item as the proportions in an area may have been an indication of local culture that would be expressed within the still to be formed primary care groups and primary care trusts (McGruer, 2000). The Audit Commission (1999) had noted the distorting effect of GP fundholding in relation to district nursing establishments, i.e., allocation according to GP contract specification rather than to population need. The authors were unable to find direct evidence concerning the impact of a high proportion of single-handed practices on district nursing provision, but practical experience suggested that dealing with a number of different practices is more time consuming than dealing with one or two group practices. In a previous survey of community nursing (Dunnell and Dobbs, 1982) nurses commented on the time taken to liaise with a number of different practices.

The majority of the questionnaire items related 


\begin{tabular}{|c|c|}
\hline Items & Rationale (experience based) \\
\hline \multicolumn{2}{|l|}{$\begin{array}{l}\text { Structural factors that might promote or hinder the } \\
\text { ability of district murses to deliver acute care }\end{array}$} \\
\hline Geographical location of trust & $\begin{array}{l}\text { Volume of traffic/difficulty parking/distances to be } \\
\text { covered. To be used to compare and contrast trusts } \\
\text { in Part } 2 \text { of the study. }\end{array}$ \\
\hline Location of district general hospital within the trust & $\begin{array}{l}\text { Better liaisons across care sectors if DGH is easily } \\
\text { accessible? }\end{array}$ \\
\hline $\begin{array}{l}\text { Presence of community hospitals and hospices } \\
\text { within the trust }\end{array}$ & Represent a back up facility for district nurses? \\
\hline Composition of district nursing teams & $\begin{array}{l}\text { Richer skill mix enables critical care decisions to be } \\
\text { taken. }\end{array}$ \\
\hline \multicolumn{2}{|l|}{$\begin{array}{l}\text { Organizational factors likely to impinge on the } \\
\text { ability of district nurses to deliver acute nursing } \\
\text { care. }\end{array}$} \\
\hline $\begin{array}{l}\text { Status of trust } \\
\text { Designation and clinical background of managers }\end{array}$ & $\begin{array}{l}\text { Orientation towards the needs of the district nursing } \\
\text { service. }\end{array}$ \\
\hline $\begin{array}{l}\text { Level of GP fundholding, number of single handed } \\
\text { GPs. GP advice line, Nature of GP emergency } \\
\text { cover. }\end{array}$ & $\begin{array}{l}\text { Contractual restrictions? Ease of access to medical } \\
\text { advice and cover. }\end{array}$ \\
\hline $\begin{array}{l}\text { Availability of a night service, social service rapid } \\
\text { response team, hospital at home team, specialist } \\
\text { nursing services }\end{array}$ & Resources already in place to deliver acute care. \\
\hline \multicolumn{2}{|l|}{ Factors concerning district nursing activity } \\
\hline $\begin{array}{l}\text { No of daily visits by members of the district nursing } \\
\text { team and average number in district nursing } \\
\text { case-loads* }\end{array}$ & Capacity to take on work. \\
\hline $\begin{array}{l}\text { Volume of work in relation to residential homes and } \\
\text { nursing homes }\end{array}$ & As above. \\
\hline Relationships with social services & $\begin{array}{l}\text { Shared commitment facilitating day to day } \\
\text { working? }\end{array}$ \\
\hline
\end{tabular}

* This is recognized as a crude measure of work-load as patient complexity and available skill mix impact on levels of activity.

Figure 1 Performance of trusts in relation to six key variables 
to resources available to the district nursing service, e.g., the provision of 24-hour nursing cover and telephone access to the district nursing service, the availability of medical equipment loans and the existence of a social services department rapid response team. Hospital-at-home schemes typically are able to offer round the clock cover (Wilson et al., 1999). The lack of 'out of hours' cover is known to impact negatively on the quality of care received by seriously ill or dying patients (Keen, 2001). Items regarding the size of caseloads and average number of visits as existing levels of activity were also included as they may impinge on the service's ability to embrace a more intensive workload. As the aim of the survey was to obtain a broad brush picture of provision, items were designed to obtain factual information of the kind a manager of a service in a particular area would be likely to have readily to hand or that they might be expected to know by dint of their role and responsibilities. The researchers were mindful of the enormous changes being wrought in terms of the then imminent formation of primary care groups and the roll out of nurse prescribing. The questionnaire was therefore designed to be short (24 items) requiring, in the majority of cases, tick box replies.

\section{Pilot Work}

The prepilot questionnaire was reviewed by a community research group at the authors' place of work, by community practice teachers and with a district nurse manager and a district nurse working within an elderly hospital at home scheme. The questionnaire was tested with two experienced district nurses, both working within the same hospitalat-home team to establish the level of consistency of the answers in relation to the individual items on the schedule. Since the hospital at home team had a trust-wide remit, it was felt that nurses working within the team would be likely to have an overview of district nursing provision and be able to provide a more consistent broad brush average figure than district nurses working in local teams. 'Local' district nurses might have been affected by fluctuations in caseload numbers that were of a temporary nature, e.g., admitting a patient for terminal care who required intensive visiting, but for a relatively short period. As information was being sought from the total population of community trusts an independent pilot study was not conducted. However an initial mail out of the first 16 trusts (in the order in which their entries occurred in the Community Handbook) was used to assess whether the questions appeared clear to the respondents, judged by whether appropriate responses were returned.

\section{Validity}

Those district nurses, managers and district nurse lecturers who were consulted considered that the instrument had face validity. In relation to the clarity of the questions, responses from the initial mail out of 16 questionnaires indicated that one question which was related to the status of the trust was not fully understood and so it was amended in subsequent questionnaires to read 'Does your trust cover ...?' followed by a list of options.

\section{Reliability}

Regarding the reliability of the instrument, the two district nurse respondents working within a hospital-at-home team (with a trust-wide remit and having an overview of district nursing activity) differed slightly in their answers to two questions: firstly, the number of visits carried out by a $G$ grade district nurse in a day; respondent one stating five and the other five-to-eight visits. Secondly, there were differences in the reported average caseload size. One respondent stated a figure of 45 , while the other respondent stated 60. These responses may reflect that within the same area there can be a considerable degree of variance amongst district nursing. Thurlby (2001) in her study of a work-load analysis tool found that the number of patients visited in a month by district nursing teams varied between 67 and 166 within similar areas.

\section{Data analysis}

Data from the questionnaires were analysed using descriptive statistics for nominal level data and the chi-square test was used to explore associations between variables deemed to be the most important in terms of the delivery of acute and intermediate care. Certain categorical and ordinal data were transformed into dichotomies to enable cross tabulation, e.g., where trusts provided cover for 20 or more hours they were coded as 1 and those providing less than 19 hours were coded as 0 . The underlying rationale was to divide the data into categories that were considered more or less 
likely to promote the delivery of acute care at home. In the case of hours of cover, 20 hours was chosen as the cut off point as the Patient Charter (DoH, 1995) requires a district nurse to respond to an urgent referral within 4 hours. Some local district nursing caseload management frameworks also set out priority visits as those that require a response within 4 hours (Heath and Archer, 2001).

During the course of the survey a number of initiatives were announced which altered the importance of certain questions in the survey, e.g., NHS Direct (NHS Executive, 1999) which meant that the existence of an advice line was no longer likely to be a significant variable within trusts. The findings presented below are therefore those that remained of continuing relevance to the aims of the research.

\section{Findings}

\section{Response to the survey}

One hundred and twenty five questionnaires were returned initially giving a response rate of $70 \%$. Written follow-up provided a further $13 \%$ $(n=23)$ giving an overall unit response rate of $83 \%(n=148)$. In relation to the number of trusts surveyed $(n=175)$, the number of responses received was 146 , yielding a response rate of $83 \%$. During the period of the survey several trusts were in the process of reconfiguring which was thought to account for some of the unit nonresponses. In telephone follow-up of their nonrespondents the Audit Commission (1999) found that amalgamation was a prominent reason for nonresponse. Nonresponding trusts were well distributed across the country.

In this survey respondents reported a total of 98 distinct job titles, the most frequently mentioned being 'locality manager' $(n=11)$. Twenty eight respondents had titles mentioning district nursing. Fifteen respondents reported titles that suggested executive positions within their trusts. Three quarter of the respondents $(n=111)$ reported having managers within the trust with district nursing backgrounds.

\section{Structural variables}

An overall summary of the main findings relating to organizational variables and district nursing and related provision are set out in Tables 1 and
2. Items regarding the composition of a typical district nursing team and the average caseload in the area yielded a high number of item nonresponse. Caseload item nonresponse was as high as $28 \%$ ( $n$ $=41$ ). Summary and analyses of these data were rendered impracticable by the nature of the responses with some respondents providing trustwide figures, rather than figures for typical teams and caseloads. One hundred and thirty nine respondents provided estimates of the number of daily visits carried out by district nurses and 141 provided figures for staff nurse visits. The mean number of daily visits for $\mathrm{G}$ grade nurses was 9.8 with a median of 10 and a standard deviation of 3.176. The mean number of visits carried out by community staff nurses was 12 with a median of 12 and a standard deviation of 3.395 .

\section{Availability of the service}

The majority of respondents $(93 \%, n=138)$ reported that their trust operated an evening service. Seven were available on an 'on-call basis' only. Nearly three quarters of respondents $(73 \%$, $n=108$ ) reported some form of night cover. Twenty five of these stated that the service was available on an 'on-call' basis or on an 'ad hoc' or ' patient-specific' basis, e.g., for terminal care. One respondent noted that the service was not for emergency use. Amongst the responses there was enormous variation in the hours that the evening and night services were available. The data were summarized to present those trusts where the service was available for 20 out of 24 hours for the reasons outlined above. Just half of trusts $(54 \%$ of $n=80$ ) provided a service for 20 or more hours within a 24-hour period.

Trusts were ranked according to their performance on six key variables relating to the delivery of acute nursing care in the home, e.g., provision of 20 hours or more of nursing cover; patients and others able to contact the service directly day and night; rapid access to medical aids and access at the weekends; nine or less visits per day performed by the district nursing sister, and the availability of a hospital-at-home team. Trusts were awarded one point for each of these variables (maximum total achievable, 6) and ranked according to overall scores. Ranking the trusts according to their performance on selected key variables produced seven distinct groups (see Figure 2).

The second objective of the study was to estab- 
Table 1 Survey findings relating to organizational variables and district nursing and other provision

Questionnaire item $\quad$ No. of responses \% Number

\section{(a) Organisational variables}

Trust status:

148

Community only

Community and acute hospital

Community, mental health and learning disability

No. of responses \%

Number

All

Levels of GP fundholding

$>50 \%$

$<49 \%$

Single handed GPs

$>50 \%$

$<49 \%$

145

Provision of emergency cover

Entirely by GP

Separate service

Mixture

\section{(b) District nursing and related provision}

Amount of tine spent in residential homes

148

A great deal of time
A little/some time

Amount of tine spent in nursing homes

A great deal of time
A little/some time

148

148

Existence of hospital-at-home/rapid response/intermediate care team

Yes

Did not mention

$\begin{array}{rr}11 & 17 \\ 9 & 13 \\ 55 & 81 \\ 25 & 37\end{array}$

$25 \quad 37$

3
81
37

$43 \quad 63$

Existence of palliative care team

Yes

Did not mention

$\begin{array}{rr}8 & 12 \\ 92 & 133\end{array}$

$92 \quad 133$

Macmillan service

Yes

Did not mention

$\begin{array}{rr}1 & 2 \\ 7 & 10 \\ 92 & 136\end{array}$

\section{(c) Availability of district nursing service}

District nurse can be contacted directly over 24 hours

(pager/telephone)

Yes

No

Availability of service ' out of hours'
Evening service*
Yes

No

Night service*

Yes

No

Access to nursing aids within a few hours

$\begin{array}{rl}42 & 60 \\ 34 & 48 \\ 8 & 12 \\ 16 & 23\end{array}$


Table 1 Continued

\begin{tabular}{|c|c|c|c|}
\hline Questionnaire item & No. of responses & $\%$ & Number \\
\hline $\begin{array}{l}\text { Access to nursing aids at the weekend } \\
\text { Yes } \\
\text { No }\end{array}$ & 134 & $\begin{array}{l}63 \\
37\end{array}$ & $\begin{array}{l}84 \\
50\end{array}$ \\
\hline \multicolumn{4}{|l|}{ (d) Variables relating to social service departments } \\
\hline $\begin{array}{l}\text { Existence of a social service department rapid response team } \\
\text { Yes } \\
\text { No }\end{array}$ & 148 & $\begin{array}{l}41 \\
59\end{array}$ & $\begin{array}{l}60 \\
88\end{array}$ \\
\hline $\begin{array}{l}\text { Working relations with social services } \\
\text { Good } \\
\text { Okay } \\
\text { Mixed } \\
\text { Poor }\end{array}$ & 148 & $\begin{array}{r}54 \\
41 \\
4 \\
1\end{array}$ & $\begin{array}{r}80 \\
61 \\
5 \\
2\end{array}$ \\
\hline
\end{tabular}

Table 2 Relationships between structural, organizational and process variables

\begin{tabular}{lll}
\hline Variable & Variable & Statistical result \\
\hline Trust status & Trusts with district nursing service available for at least & $\chi^{2}=3.968 \mathrm{DF}=3, \mathrm{NS}$ \\
& 20 hours out of 24 & \\
& Nine or less DN visits daily & $\chi^{2}=4.730 \mathrm{DF}=3, \mathrm{NS}$ \\
& Service contactable over 24 hours & $\chi^{2}=2.221 \mathrm{DF}=3, \mathrm{NS}$ \\
& Able to obtain medical loans within a few hours & $\chi^{2}=3.165 \mathrm{DF}=3, \mathrm{NS}$ \\
& Able to access medical loans at the weekend & $\chi^{2}=6.489 \mathrm{DF}=3, \mathrm{NS}$ \\
& Able to obtain medical loans within 24 hours & $\chi^{2}=1.610 \mathrm{DF}=3, \mathrm{NS}$ \\
& Hospital at home & $\chi^{2}=2.379 \mathrm{DF}=3, \mathrm{NS}$ \\
Service available & Working relationship & $\chi^{2}=11.262 \mathrm{DF}=3, \mathrm{P}<0.02$ \\
$>$ 20 hours in 24 & Commungers with district nursing qualification & $\chi^{2}=1.160 \mathrm{DF}=3, \mathrm{NS}$ \\
& Hospice provision & $\chi^{2}=0.074 \mathrm{DF}=1, \mathrm{NS}$ \\
No. of DN visits & Time spent in residential homes & $\chi^{2}=1.843 \mathrm{DF}=1, \mathrm{NS}$ \\
\hline
\end{tabular}

lish whether there was a relationship between structural and organizational factors and district nursing activity. In only one case was a statistically significant relationship established using the chisquare test.

Trust status was significantly related to the extent to which respondents reported that they experienced good working relationships with social service departments. Table 2 presents the results of the remaining cross tabulations.

\section{Discussion}

The findings of this survey suggest that in the majority of trusts in England district nurses lacked the resources to deliver acute or intermediate nursing care at home. When ranked according to performance on key variables 118 trusts scored three or less. Only two trusts scored the maximum six points. Six trusts scored zero. Practical experience suggests that in order to care for acutely ill patients 


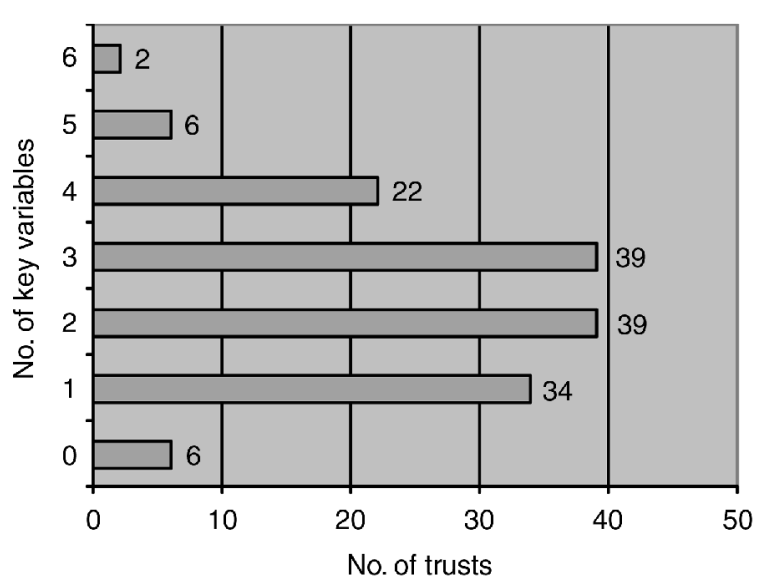

Figure 2 Questionnaire items and rationales for inclusion

or those recovering from acute illness at home the district nursing service needs to be available outside normal working hours. Patients, carers and other health professionals need to be able to contact the service for nursing needs that do not necessarily need medical oversight or the emergency services. Although well over two thirds of the trusts reported some form of night cover some of these responses included on-call, ad hoc and 'patient-specific' arrangements, e.g., for palliative care patients. According to the Audit Commission (1999) more district nursing around the clock is needed if the service is to respond to the wishes and needs of service users and yet it is reported that the service could be contacted directly in less than a quarter of the trusts surveyed. The facility to leave messages by answerphone was excluded from this analysis as there can be as long as 15 hours between a message being left after day staff have gone home and the next day's shift picking up a message.

In order to prevent unnecessary admission to hospital or complications of acute illness such as pressure sores, rapid access to nursing aids such as commodes and pressure-relieving devices is required. Acutely sick patients are also likely to have high levels of social care need. Rapid access to nursing aids was only reported to be available in just over two fifths of the trusts. Again only in well under half of the trusts could district nurses call on the services of a social service department rapid response team.

The need for such trust-wide services may be obviated if dedicated hospital-at-home teams exist in the area. Surprisingly, a relatively small number of respondents reported the existence of such teams $20 \%(n=29)$. If palliative care teams are included in this provision the number of trusts reported being able to provide enhanced nursing care at home rose to $36 \%(n=54)$. It is unclear whether respondents excluded or included those teams which arose from winter pressures initiatives (Emergency Services Team, 1999) and were of a temporary nature. However, the Audit Commission (1999) in their survey found that $30 \%$ of trusts in England and Wales had hospital-at-home teams, though their figures appear to include paediatric hospital-at-home schemes which were excluded in this study.

Another surprising feature of the responses was the high number of daily visits being undertaken by qualified staff, in particular, by the district nurse team leaders. The average number of 9.8 visits appears excessively high. Ross and Bower (1995) in their study testing the feasibility of the SAFE assessment tool in district nursing found that to use the basic tools took a mean time of 39.3 minutes. This time did not include condition specific assessments or assessments such as those for moving and handling or indeed the delivery of any nursing care. It speaks for itself that individual district nurses cannot perform 10 detailed assessments together with the necessary recording, referral and care provision within a working day. The number of visits reported suggests that district nurses are carrying out visits that are other than initial assessment and reassessment visits. Of course, questions must be asked in relation to the validity and reliability of the data. As one of the respondents remarked the figures should not be taken to represent 'rocket science'. Another respondent remarked that she had extracted the figures from the trust activity data base so that they were probably unreliable! Measuring activity and dependency on the district nursing service continues to be a challenging area (Audit Commission, 1999; Thurlby, 2001).

During pilot work the two respondents from the same trust had varied in their response to the item on the average number in a district nursing caseload. As discussed earlier the data for this item 
obtained in the main survey were deemed to lack validity and analysis was not attempted. In one case where the data appeared particularly anomalous the respondent was contacted. He had not been able to provide an average number, but had given an area-wide number. It has been noted that contact figures are inadequate for monitoring caseloads because they are not based on case mix (Audit Commission, 1999). That respondents had difficulty replying to this item may be related to how difficult it seems to measure district nursing activity. The notion of an 'average' caseload may be difficult to measure because of the variation to be found within trusts. The Audit Commission (1999) reported that caseloads varied from between less than 20 to more than 40 patients per whole time equivalent team member. It is not clear though from their report whether this included all team members or only qualified staff.

A further explanation for the findings in relation to caseload numbers could be that managers do not have to hand sufficient information about the district nursing service. Although a significant number of trusts reported nurses with district nursing qualifications amongst their managers it is not clear whether all of these were involved in the management of the district nursing service itself. The enormous number of job titles reported by the respondents suggests that managers have wide remits and care of the district nursing service was but one of several responsibilities. More in-depth investigation would be required to establish whether this was indeed the case.

There appeared to be a relationship between trust status and the reporting of good working relationships. This is an area that warrants further investigation as recent government policy has placed much emphasis on the need for health and social service departments to work together (DoH, 1998).

\section{Limitations of the survey}

As the Audit Commission (1999) pointed out district nursing is a complex service. It would have been an impossible task to try to capture this complexity within a postal survey. This survey did not set out to gain in-depth information from each of the trusts and inevitably in asking broad questions little detail was gained. It is clear, however, from the data obtained and from the findings of an earlier Audit Commission (1999) survey in 1997 that exact data on a number of key variables, such as patient contacts, etc., are not easily available even to those who have responsibilities for the service within trusts and therefore more precise questions would have been unlikely to have produced better results. The researchers recognized that there also existed much variation within trusts particularly in relation to factors such as night cover, caseload numbers and daily visits. The respondents were asked to list the specialist teams and services operating within their trust, rather than asked directly whether their trust operated a hospital-athome team. The surprisingly small number of hospital-at-home teams reported may have been a function of question phrasing though the results are similar to those reported by the Audit Commission (1999), bearing in mind that the Commission reported findings from both England and Wales.

The results of this survey also suggest a curious neglect of the district nursing service on the part of successive governments at a time when the service is most needed. Investment in new intermediate care services may mask the decline of the service. The diversion of district nurses to servicing the needs of general practice surgeries within primary care trusts may result in even further depletion of the service. There is anecdotal evidence that the latter is already happening.

The NHS Plan (DoH, 2000b) and the National Service Framework for Older People (DoH, 2001) rightly emphasize the need for rehabilitation. Intermediate care services are seen as a means of facilitating the care closer to home scenario, but there seems to be a tacit and optimistic assumption that people will be returned to a level of independence that will obviate the need for high levels of nursing and social care. Much has still to be learnt about the health trajectory of the old elderly (UKCC, 1997) and cohort effects may play an important part in the health of successive groups of older people. Nonetheless a failure to provide adequate resources to care for those who have long-term nursing needs after they have been discharged from hospital or intermediate care will mean that pressure will continue to be felt in other parts of the health care system, particularly in the acute sector. 


\section{Conclusion}

The survey was planned and undertaken at a time of rapid change and reorganization in primary care and inevitably the survey data will, to a certain extent, already be historical in some areas. Nonetheless the findings suggest that an enormous investment in district nursing will need to be made nationally to redress the lack of provision in relation to the key variables outlined in this study. To date, there is no evidence to suggest that this has been the case.

The recently formed primary care groups, and since April 2000 primary care trusts, will be commissioning acute and primary care services and will need evidence on which to base decisions relating to the provision of intermediate care and long-term community nursing care. District nursing is a long established service with much experience of nursing outside acute hospitals (Audit Commission, 1999). Harnessing this expertise and investing in enhanced district nursing services may be one part of the solution to meeting intermediate and long-term care needs. However, information is needed both on the effectiveness of this option and its acceptability to a number of key individuals including patients, general practitioners and social services departments not to mention district nurses themselves.

\section{Acknowledgements}

The authors would like to thank all those who made time to participate in the survey at an exceptionally busy time for community trusts.

\section{References}

Audit Commission 1992: Lying in wait: The use of medical beds in acute hospitals. London: HMSO.

Audit Commission 1999: First assessment, a review of district nursing services in England and Wales. London: Audit Commission.

Carr Hill, R., Hardman, G., Martin, S., Peacock, S., Sheldon, T. and Smith, P. 1994: A formula for distributing NHS revenues based on small area use of hospital beds. Occasional paper: University of York.

Department of Health 1995: The patient's charter. London: Department of Health.

Department of Health 1998 : Partnership in action: New opport- unities for joint working between health and social services. London: Department of Health.

Department of Health 2000a: Shaping the future NHS: Long term planning for hospitals and related services. Consultation document on the findings of the National beds inquiry, supporting analysis. London: Department of Health.

Department of Health 2000b: The NHS plan. A plan for investment. A plan for reform. London: The Stationery Office.

Department of Health 2001: National service framework for older people. London: Department of Health.

Donald, I.P., Baldwin, N.R. and Bannerjee, M. 1995: Gloucester hospital-at-home. A randomized controlled trial. Age and Ageing 24, 434-39.

Dunnell, K. and Dobbs, J. 1982: Nurses working in the community. London: HMSO.

Edwards, M 1998: Primary health care. In Hinchcliffe, J., Norman, S., Scrober, J., editors, Nursing practice in health care, 3rd edn. London: Arnold.

Emergency Services Action Team 1999: ESAT Report online. Available: http://www.doh.gov.uk/pub/docs/doh/esat99.pdf. Retrieved 15 August 2000.

Heath, J. and Archer, C. 2001: Whole systems caseload management framework for district nursing. Primary Care Nursing 14-16.

Griffiths, P. 1998: Evaluation of a nursing led in-patient service. Unpublished $\mathrm{PhD}$, King's College London.

Handbook of Community Nursing 1998: Chichester: Professional, Managerial \& Healthcare Publications Ltd.

Keen, A. 2001: Hospital at home. Primary Care Nursing 8.

Knoweldon, J., Westlake, L., Wright, K.G. and Clark, S.J. 1991: Peterborough hospital at home: an evaluation. J Public Health Medicine 13, 182-88.

McGruer, C. 2000: The public health role in nursing and health visiting within primary care: a study of the views of primary care group board nurses. Unpublished MSc thesis, King's College London.

Mowat, I.G. and Morgan, R.T.T. 1982: Peterborough hospital at home scheme. British Medical Journal 284, 641-43.

NHS Executive 1999: NHS direct. Online available at http://www.doh.gov.uk/hhsexec/direct.htm. Retrieved 16 August 2000.

NHS and Community Care Act 1990: Chapter 19. London: HMSO.

NHS Act 1999: Chapter 8. London: The Stationery Office.

Ross, F. and Bower, B. 1995: Standardized assessment for elderly people SAFE - a feasibility study in district nursing. Journal of Clinical Nursing 4, 303-10.

Ryrie, I. and Edwards, M. 1998: Assessment and planning care for elderly people. In Redfern, S., Ross, F.M., editors, Nursing older people. London: Churchill Livingstone, 163-82.

Skeet, M. 1978: Division of labour: roles, responsibilities and accountability within the team concept. In Hardie, M., Hockey, L., editors, Nursing auxiliaries in health care. London: Croom Helm, 27-41.

Steiner, A. 1997: Intermediate care: A conceptual framework and review of the literature. Kings Fund: London.

Primary Health Care Research and Development 2003; 4: 353-364 
Thurlby, K. 2001: An adaptation of the Easley-Storfjell CL/WL analysis instrument and a test of its validity when used by community nurses: a pilot study. Unpublished MSc thesis, King's College London.

Wilson, A., Parker, H., Wynn, A., Jagger, C., Spiers, N., Jones, J. and Parker, G. 1999: Randomised controlled trial of effec- tiveness of Leicester hospital at home scheme compared with hospital care. British Medical Journal 319, 1542-46.

UKCC 1997: The nursing and health visiting contribution to the continuing care of older people. London: UKCC.

Young, L. 1999: Tribalism is out. Practice nursing and district nursing, integrating the two disciplines. Nursing Times 95, 60. 